Submit to Communications in Physics, (2020), pp. 27-34

DOI:10.15625/0868-3166/30/1/13904

\title{
VIBRATIONAL STUDY OF THE HYDROGEN ADSORPTION ON THE MISSING ROW PLATINUM (110) SURFACE
}

\author{
TRAN THI THU HANH ${ }^{\dagger}$ AND NGUYEN VAN HOA \\ Applied Science Faculty, Ho Chi Minh city University of Technology - VNU HCM, Vietnam \\ ${ }^{\dagger}$ E-mail: thuhanhsp@gmail.com
}

Received 28 June 2019

Accepted for publication 20 December 2019

Published 28 February 2020

\begin{abstract}
The hydrogen vibration was investigated to analyze its affect on the hydrogen adsorption on the missing row platinum surface (H/Pt(110)-(1x2) model) in the ultrahigh vacuum (UHV). The density functional theory (DFT) combined with the approximation oscillation of the hydrogen atom on the surface was used. When the hydrogen coverage $\Theta_{H}$ on the surface is $100 \%\left(\Theta_{H}=1\right.$ $M L)$, and taking into account the vibrational effect, the bond formed at the edge of the first layer (short bridge) is the most stable site. The vibrational effect on the adsorption model H/Pt(110)(1x2) is significant.
\end{abstract}

Keywords: vibration, hydrogen adsorption, the missing row $\operatorname{Pt}(110)-(1 \times 2)$ surface, the density functional theory.

Classification numbers: 31.15.E; 33.20.Vq; 68.43.-h.

\section{INTRODUCTION}

In recent years, the electrochemical surface has been considered as a science that affects many different areas such as microelectronics, catalysts, fuel cells [1,2]. In particular, the electroadsorption of the hydrogen atom $(\mathrm{H}$ atom) on the platinum surface $(\mathrm{Pt})$ is considered as one of the intensive research models [3-12].

The hydrogen adsorption occurs from acidic or aqueous solutions. It also can be accomplished from non-aqueous solutions which are able to dissolve the hydrogen containing acids. Firstly, the proton $\mathrm{H}^{+}$of the solvent combines with the water molecule $\mathrm{H}_{2} \mathrm{O}$ forming $\mathrm{H}_{3} \mathrm{O}^{+}$[9].

(C)2020 Vietnam Academy of Science and Technology 
Then $\mathrm{H}_{3} \mathrm{O}^{+}$discharges to give the adsorbed $H$ atom [9] (Volmer step):

$$
M+H^{+}+e^{-\stackrel{E}{\rightarrow}} M-H_{a d s}
$$

where $M$ is the surface atom of the metal, $E$ is the electrode potential. Then, two adsorbed $H$ atoms recombine to yield $\mathrm{H}_{2}$ as following (Tafel step):

$$
2 M-H_{a d s} \rightarrow 2 M+H_{2}
$$

or (Heyrovsky step)

$$
H^{+}+e^{-}+M-H_{a d s} \stackrel{E}{\rightarrow} M+H_{2}
$$

Because Pt has four different types of surface structures $\operatorname{Pt}(111), \operatorname{Pt}(100), \operatorname{Pt}(110)$ and $\operatorname{Pt}(110)-(1 \times 2)$, there have been many studies for the hydrogen adsorption on these surfaces. Gudmundsdóttir et al. and Skúlason et al. performed theoretical calculations to clarify the effect of the faces $(111)$ and $(100)[13,14]$. Then, the experiment and theory were used to further study the adsorption of $\mathrm{H}$ atom on $\mathrm{Pt}(110)$ and $\mathrm{Pt}(110)-(1 \times 2)$ surfaces [15-20]. Especially for the $\mathrm{Pt}(110)-$ $(1 \times 2)$ surface, many different research results on the stable adsorption sites of $\mathrm{H}$ atom on the surface were given. The most stable trough site was shown in the studies using the LEED (lowenergy electron diffraction) and the vibrational spectroscopy measurements [21-23]. Meanwhile, Zhang et al. and Minca et al. used the LEED experiment and the DFT calculation methods and found the most stable position at the short bridge site for the small coverage $\sim 0.5$ ML $[17,18]$. Gudmundsdóttir et al. [23] confirmed again that the most stable site is the short bridge site at the low coverage when using the temperature-programmed desorption (TPD) and the DFT calculations. However, at high coverage, the strongest sites are on the micro-facet or in the trough [24].

The binding position of the $\mathrm{H}$ atoms on the platinum surface plays an important role in the electrochemical surface research, but the difference in the binding energy of the stable sites is quite small, so it is necessary to study the vibrational effect of $\mathrm{H}$ on the surface. Dino et al. [25] showed that the links between theory and experiment are more convincing when vibrational effect calculations are taken into account. The molecular dynamics simulation results show that the vibrational effect is very sensitive to pore dimensions in the research of Kurma et al. [26]. And in the reseach for $\mathrm{H} / \mathrm{Pt}(111)$ model [7], the adsorption capacity of the $\mathrm{H}$ on the Pt surface is significantly affected when taking into account the vibrational effect. Therefore, in the study of the hydrogen adsorption on the missing row $\mathrm{Pt}(110)-(1 \times 2)$ surface, we decided to conduct a research of the hydrogen vibration.

The first goal in this study is to determine the adsorption energy of the H/Pt model. Calculations of the isothermal adsorption for $\mathrm{H} / \mathrm{Pt}(110)-(1 \times 2)$ system were done using the SIESTA (Spanish Initiative for Electronic Simulations with Thousands of Atoms) simulation software. With careful inspection of the initial parameters used in the calculation by checking the convergence of layers and k-points, the energy data obtained from our DFT calculation is highly accurate. Then, the $\mathrm{H}$ atoms were let oscillate on the $\mathrm{Pt}(110)-(1 \times 2)$ surface, the vibration is studied and expressed in two value: the vibrational frequency and the zero point energy (ZPE). 


\section{CALCULATION METHODS}

\section{II.1. DFT calculation}

This study was applied the DFT calculation method for the room temperature. We used the SIESTA simulation software $[19,21]$ to calculate the electronic structures. The generalized gradient approximation (GGA) to the exchange-correlation function due to the revised Perdew, Burke, and Ernzerhof (PBE) was used in the DFT calculation. The adsorption sites of the $\mathrm{H}$ atoms on the missing row $\mathrm{Pt}(110)-(1 \times 2)$ surface are shown in Fig. 1. The basic SIESTA calculation parameters were: the double-zeta polarized (DZP) basic set, the mesh-cutoff of $200 \mathrm{Ry}$, the Fermi Dirac function with the electronic temperature of $300 \mathrm{~K}$ for the Brillouin zone integrations. The energy shift for the platinum is $200 \mathrm{meV}$, which determines the cutoff radius per angular momentum channel. And for the $\mathrm{H}$ atoms, the energy shift is $60 \mathrm{meV}$ with the split norm of 0.53 for the second zeta. These calculation parameters in SIESTA provide reasonable accuracy for the results of bare $\mathrm{Pt}$ (non-adsorbed $\mathrm{H}$ ) and the adsorption of the $\mathrm{H}$ atoms [7]. We also chose the value of $3.9242 \AA$ corresponding to the obtained experimental data [24] to build the platinum model.

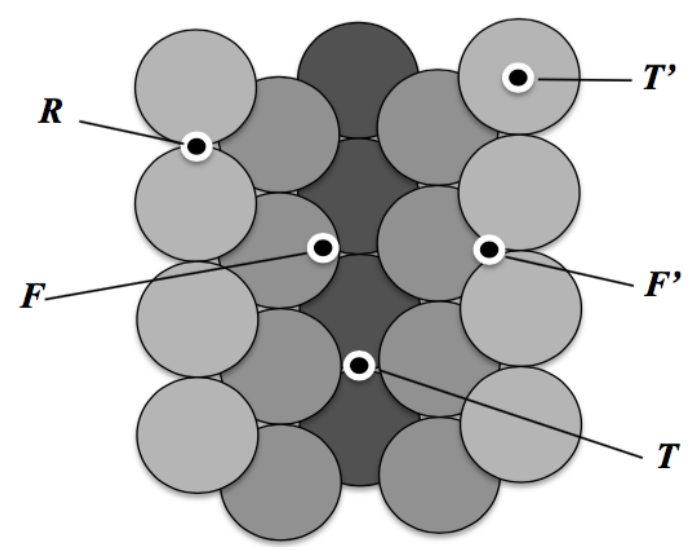

Fig. 1. The model of $\operatorname{Pt}(110)-(1 \times 2)$ surface onto which $\mathrm{H}$ atoms were adsorbed. $\mathrm{R}$ is the short bridge on the ridge site, $F$ is the on-top on the micro facet, F' is the hcp hollow site, $\mathrm{T}^{\prime}$ is the on-top on the ridge site, and $\mathrm{T}$ is the long bridge site in the trough.

The calculation of the $\mathrm{H}$ adsorption on the $\mathrm{Pt}(110)-(1 \times 2)$ surface is done through three main steps. First, the missing row $\operatorname{Pt}(110)-(1 \times 2)$ surface model is built with different atomic layers from 4 to $6 \mathrm{Pt}$ layers. For each case, the k-points in the SIESTA calculation gradually increases from $(4 \times 4 \times 1)$ to $(13 \times 13 \times 1)$ Monkhorst Pack (MP), or from 11 to $85 \mathrm{k}$-points, for the purpose of finding the convergence according to the number of layers and k-points. Secondly, after running the SIESTA program and obtaining the relaxing Pt model, we let the $\mathrm{H}$ atoms adsorb on the different positions on the $\operatorname{Pt}(110)-(1 \times 2)$ surface. These locations include fcc $(F)$, hcp $\left(F^{\prime}\right)$, short bridge $(R)$, top $\left(T^{\prime}\right)$ and trough $(T)$ sites (Fig. 1). Third, to calculate the ZPE, the $H$ atom is let oscillate around the equilibrium position along the $x, y$ and $z$ axes by the harmonic oscillation.

\section{II.2. Vibrational frequency calculation}

The oscillation of the $\mathrm{H}$ atom around the equilibrium position on each axis may be considered as the harmonic approximation oscillation because the distance between the $\mathrm{Pt}$ and $\mathrm{H}$ atoms 
is quite large compared to the oscillation of the $\mathrm{H}$ atom around the equilibrium position (see Table 1). Therefore, we use the harmonic approximation to calculate the vibrational frequency and ZPE. First, we chose the equilibrium position as the adsorption position after optimizing the H/Pt model. Next, we displace the $\mathrm{H}$ atom around the equilibrium position along the $x, y$ and $z$ axes with the value from $-0.1 \AA$ to $+0.1 \AA$, and then we calculate its energies. The obtained energy equals the energy of the harmonic oscillation:

$$
E=\frac{1}{2} k x^{2}
$$

where $x(\AA)$ is the displacement from the equilibrium position of the $\mathrm{H}$ atom, the coefficient $k$ $\left(\mathrm{eV} / \AA^{2}\right)$ is the force constant. And the value of force constant $\mathrm{k}$ is found by using the method of minimum square calculation. Then, we use the $\mathrm{k}$ value to continue calculating the vibrational frequencies in the interaction of the $\mathrm{H}$ atom with the metal surface $\operatorname{Pt}(110)-(1 \times 2)$. The expression of the frequency has the following form:

$$
\widetilde{v}=\frac{1}{2 \pi c} \sqrt{\frac{k\left(m_{1}+m_{2}\right)}{m_{1} m_{2}}}
$$

where $c$ is the speed of light, $m_{1}$ is the mass of $H$ atom, $m_{2}$ is the mass of platinum atom. Finally, the ZPE is calculated via

$$
\varepsilon=\frac{h v}{2}=\frac{h c}{2 \lambda}=\frac{h c \tilde{v}}{2}
$$

where $h$ is Planck's constant.

\section{RESULT AND DISCUSSION}

\section{III.1. Energy convergence}

For each type of Pt surface structure, the stable sites of $\mathrm{H}$ adsorption on it are also different. Therefore, we begin by calculating the surface adsorption energy with SIESTA software to verify again possible adsorption sites of $\mathrm{H}$ on the $\mathrm{Pt}(110)-(1 \times 2)$ surface. The adsorption energy of model is calculated by the formula:

$$
E_{a d s}=E_{t o t}\left(N_{H}\right)-E_{t o t}(0)-\frac{N_{H}}{2} E_{H_{2}}
$$

where $E_{\text {tot }}\left(N_{H}\right)$ is the total energy of the $\left(N_{H}\right) \mathrm{H}$ atoms adsorbed on the $\mathrm{Pt}(110)-(1 \times 2)$ surface, $E_{\mathrm{H}_{2}}$ is the total energy of the isolated $\mathrm{H}_{2}$ molecule, and $\mathrm{E}_{\text {ads }}$ is the adsorption energy of $\mathrm{H}$ on $\mathrm{Pt}$. We found the $\mathrm{E}_{\mathrm{ads}}$ at the short position $(\mathrm{R})$ are recorded as the lowest value, which means the most stable adsorption site (Table 2).

Table 1. The Pt-H bond length $(\AA)$ after optimized H/Pt system.

\begin{tabular}{cccccc}
\hline Pt layers & $T^{\prime}$ site & $F$ site & $F^{\prime}$ site & $R$ site & $T$ site \\
\hline 4 & 1.57 & 1.82 & 1.58 & 1.77 & 1.77 \\
\hline
\end{tabular}


Table 2. Adsorption energy (eV) of $\mathrm{H}$ on Pt(110)-(1x2) when using 25 k-points and $1 \mathrm{ML}$ of the hydrogen coverage $\left(\Theta_{\mathrm{H}}\right)$.

\begin{tabular}{ccccccc}
\hline Unit cell & Pt layers & T' site & F site & F' site & R site & T site \\
\hline$(1 \times 2)$ & 4 & -0.513 & -0.535 & -0.557 & -0.762 & -0.602 \\
\hline
\end{tabular}

To verify the correctness of the selected parameters in the DFT calculation, the energy convergence is calculated in detail in this study. When the energy value is converged at one point, the selected parameters are highly accurate and can be used as a comparison with experiment. The purpose of examining various number of layers and k-points is to find the value of the calculated parameters at which the energies are converged.

Table 3. The adsorption energy of the $\mathrm{H}$ atom on the missing row $\mathrm{Pt}(110)-(1 \times 2)$ surface on the R site and the F site.

\begin{tabular}{ccccccccccc}
\hline Pt & \multicolumn{2}{c}{$(4 \times 4 \times 1) \mathrm{MP}$} & \multicolumn{2}{c}{$(5 \times 5 \times 1) \mathrm{MP}$} & \multicolumn{2}{c}{$(7 \times 7 \times 1) \mathrm{MP}$} & \multicolumn{2}{c}{$(11 \times 11 \times 1) \mathrm{MP}$} & \multicolumn{2}{c}{$(13 \times 13 \times 1) \mathrm{MP}$} \\
\cline { 2 - 10 } layers & $\mathrm{R}$ & $\mathrm{F}$ & $\mathrm{R}$ & $\mathrm{F}$ & $\mathrm{R}$ & $\mathrm{F}$ & $\mathrm{R}$ & $\mathrm{F}$ & $\mathrm{R}$ & $\mathrm{F}$ \\
\hline 4 & -0.66 & -0.68 & -0.75 & -0.59 & -0.76 & -0.53 & -0.78 & -0.56 & -0.77 & -0.57 \\
\hline 5 & -0.57 & -0.45 & -0.66 & -0.52 & -0.62 & -0.52 & -0.66 & -0.55 & -0.65 & -0.54 \\
\hline
\end{tabular}

The calculations is done using the $(1 \times 2)$ lateral unit cell with the different Pt layers and k-points, on which the $\mathrm{H}$ atoms are let adsorb on the most stable sites: on the short bridge (R), and on the fcc (F) sites. Table 3 shows the adsorption energies of the $\mathrm{H}$ atom on the $\mathrm{Pt}(110)-(1 \times 2)$ surface with the k-points changed from $(4 \times 4 \times 1)$ to $(13 \times 13 \times 1)$.

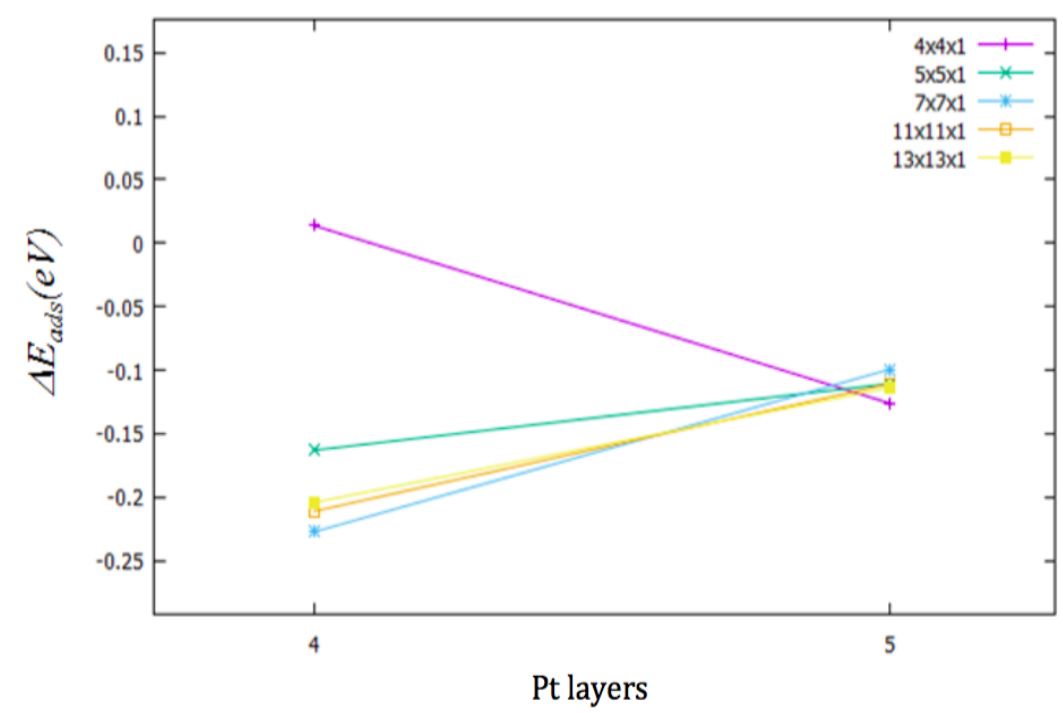

Fig. 2. Dependence of Pt layer thickness on the $\Delta \mathrm{E}_{\mathrm{ads}}$. 


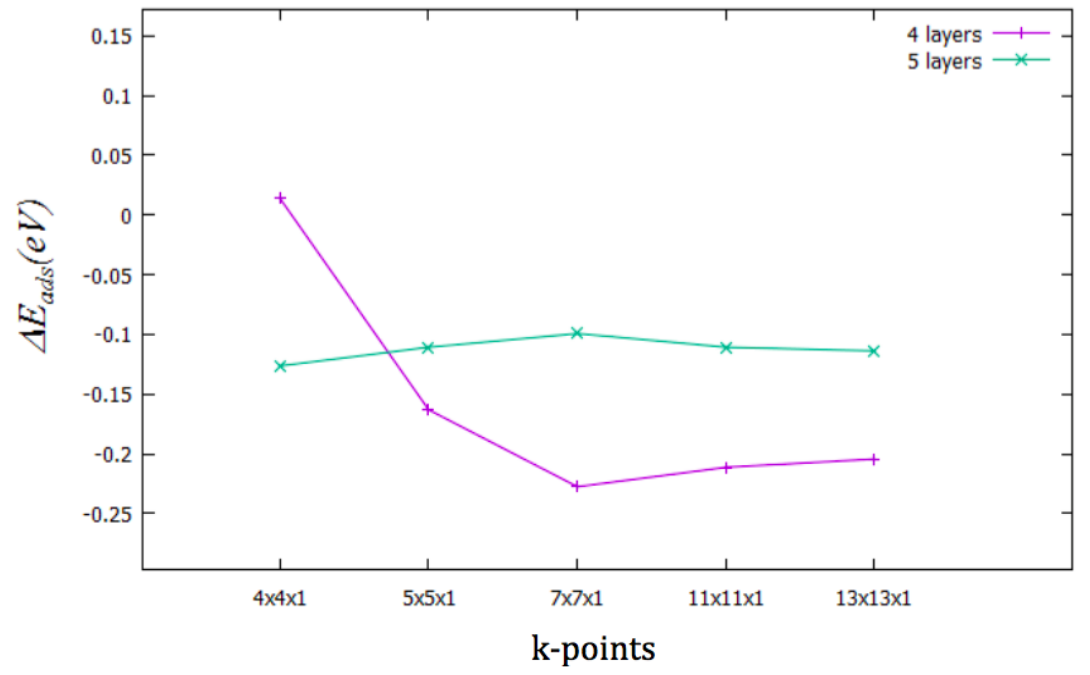

Fig. 3. Dependence of $\mathrm{k}$-points on the $\Delta \mathrm{E}_{\mathrm{ads}}$.

From Fig. 2 and Fig. 3, we visualize the data of Table 3. In Fig. 2, it can be seen that when the number of platinum layers is increased to 5 , the value $\Delta \mathrm{E}_{\mathrm{ads}}$ (the adsorption energy on the short bridge relative to that on the fcc) becomes convergence with different k-points. This indicates that $\mathrm{H}$ atom only affects 4 top Pt layers. Fig. 3 shows that the convergence value is approaching when the number of k-points increases to $(13 \times 13 \times 1)$ MP.

\section{III.2. Vibrational frequency and ZPE}

After carefully checking the converged data, we use the $(7 \times 7 \times 1)$ Monkhorst Pack grid for the number of k-points and 5 layers for the number of Pt layers.

Table 4 shows the vibrational frequencies when the coverage of $\mathrm{H}$ atom on the platinum surface is $1 \mathrm{ML}$. The obtained vibrational frequency for the surface parallel $\mathrm{x}$ component $(\mathrm{P})$ is range from $178 \mathrm{~cm}^{-1}$ to $973 \mathrm{~cm}^{-1}$. And for the surface vertical y component (V) it is range from $381 \mathrm{~cm}^{-1}$ to $1017 \mathrm{~cm}^{-1}$. It indicates that the $\mathrm{H}$ on the top site is the least fluctuating position on the $\mathrm{x}, \mathrm{y}$ axes on the Pt surface. However, the most fluctuating position on the $\mathrm{x}$ axis is the short bridge site, and on the $y$ axis it is the trough site. The vibrational frequency for the $\mathrm{H} / \mathrm{Pt}(110)-(1 \times 2)$ model is much higher than the frequency for the $\mathrm{H} / \mathrm{Pt}(111)$ model (the value is range from $53 \mathrm{~cm}^{-1}$ to 272 $\mathrm{cm}^{-1}$ ) [7] (Table 4). This proves that the mobility of the $\mathrm{H}$ atom on the $\operatorname{Pt}(110)-(1 \times 2)$ surface is more than that on the $\operatorname{Pt}(111)$ surface, and it is consistent with the missing row surface structure of the $\mathrm{Pt}(110)-(1 \times 2)$ model.

The vibrational frequency of the $\mathrm{H}$ atom on the $\mathrm{Pt}(110)-(1 \times 2)$ surface for the $\mathrm{z}$ axis (stretching frequency) is in the range of $1031 \mathrm{~cm}^{-1}$ to $2210 \mathrm{~cm}^{-1}$, in which the oscillation at the trough site is the smallest and the oscillation at the top site is the largest. The hydrogen frequency at the top site on the $\operatorname{Pt}(110)-(1 \times 2)$ surface is similar to that on the $\operatorname{Pt}(111)$ surface $\left(2100 \mathrm{~cm}^{-1}\right.$ $-2200 \mathrm{~cm}^{-1}$ ) [7, 27], and it is consistent with previous result of $2082 \mathrm{~cm}^{-1}$ from Ref. [28]. It also shows good agreement with the values of the experimental calculation using the SEIRAS (surface-enhanced infrared absorption spectroscopy) for the H/Pt system (2080-2095 cm${ }^{-1}$ ) [9]. 
This indicates that the greatest mobility of the $\mathrm{H}$ atom on the Pt surface is on the top position for the $\mathrm{z}$ axis. Besides, the obtained frequency of the $\mathrm{H}$ atom on the bridge site is nearly $1420 \mathrm{~cm}^{-1}$, which agrees well with the previous theoretical calculation $\left(\sim 1320 \mathrm{~cm}^{-1}\right)$ [29]. Table 4 shows that the frequency has the highest value when the $\mathrm{H}$ atom vibrates along the $z$ axis. This can be explained by the reason that the trough of the reconstruction surface $\operatorname{Pt}(110)-(1 \times 2)$ is very steep.

Table 4. Vibrational frequency of the $\mathrm{H}$ adsorption on the $\mathrm{Pt}(110)-(1 \times 2)$ surface.

\begin{tabular}{lccccc}
\hline & $T^{\prime}$ site & $F$ site & $F^{\prime}$ site & R site & T site \\
\hline Vibrational frequency for $\mathrm{P}\left(\mathrm{cm}^{-1}\right)$ & 178 & 728 & 815 & 319 & 973 \\
Vibrational frequency for $\mathrm{V}\left(\mathrm{cm}^{-1}\right)$ & 381 & 573 & 373 & 1017 & 609 \\
Ref. [7] for $\mathrm{H} / \mathrm{Pt}(111)$ & 277 & 145 & & & \\
Stretching frequency $\left(\mathrm{cm}^{-1}\right)$ & 2210 & 1098 & 2074 & 1421 & 1032 \\
Ref. [29] for $\mathrm{H} / \mathrm{Pt}(110)-(1 \times 2)$ & & & & 1320 & \\
Ref. [28] for $\mathrm{H} / \mathrm{Pt}(110)$ & 2082 & & & & \\
Ref. [27] for $\mathrm{H} / \mathrm{Pt}(111)$ & 2110 & & & & \\
\hline
\end{tabular}

The adsorption energy in Table 5 is calculated by adding the ZPE to the initial adsorption energy $\mathrm{E}_{\mathrm{ads}}$. It shows that the vibrational effect energy is highest $(\sim 140 \mathrm{meV})$ when the $\mathrm{H}$ atom is adsorbed on the top site. And for the most stable short bridge site, the ZPE is $\sim 88 \mathrm{meV}$. These values are in good agreement with the experimental study using the high-resolution electron energy loss spectroscopy method (149 $\mathrm{meV}$ for the top, $83 \mathrm{meV}$ for the bridge) [30].

Table 5. ZPE and adsorption energy of the $\mathrm{H}$ adsorption on the $\mathrm{Pt}(110)-(1 \times 2)$ surface.

\begin{tabular}{lccccc}
\hline & $T^{\prime}$ site & $F$ site & $F^{\prime}$ site & $R$ site & $T$ site \\
\hline ZPE $(\mathrm{eV})$ & 0.14 & 0.07 & 0.13 & 0.09 & 0.06 \\
Ref. [30] & 0.15 & & & 0.08 & \\
Adsorption energy $(\mathrm{eV})$ & -0.62 & -0.59 & -0.61 & -0.71 & -0.70 \\
\hline
\end{tabular}

We note that when adding the vibrational effect to the calculation, the adsorption energy of the system increases from $64 \mathrm{meV}$ to $137 \mathrm{meV}$ for the different adsorption sites. Before adding the vibrational effect, the most stable hydregen adsorption site of the 5 layers model is $R$, and the least stable is T', but after adding the ZPE energy, the least stable position is $\mathrm{F}$. This proves that the vibrational influence on the adsorption model $\mathrm{H} / \mathrm{Pt}(110)-(1 \times 2)$ is significant.

\section{CONCLUSION}

Using the density functional theory and the generalized gradient approximation, the vibration of the hydrogen adsorption on the missing row $\operatorname{Pt}(110)-(1 \times 2)$ surface has been studied. The adsorption calculations show that the $\mathrm{H}$ atom is the most stable at the short bridge site. The adsorption energy of the $\mathrm{H}$ atom at the position $\mathrm{R}$ increases $90 \mathrm{meV}$ when adding the vibrational 
VIBRATIONAL STUDY OF THE HYDROGEN ADSORPTION ON THE MISSING ROW PLATINUM (110) SURFACE

effect on the model. The highest stretching frequency is $\sim 2210 \mathrm{~cm}^{-1}$ when $\mathrm{H}$ atom adsorbs on the top site. The results presented in this work show that the vibrational effect on the hydrogen adsorption is significant.

\section{ACKNOWLEDGEMENT}

This research is funded by Vietnam National Foundation for Science and Technology Development (NAFOSTED) under grant number 103.01-2017.50.

\section{REFERENCES}

[1] N. Marković, B. Grgur and P. N. Ross, The Journal of Physical Chemistry B 101 (1997) 5405.

[2] K. Christmann, G. Ertl and T. Pignet, Surface Science 54 (1976) 365.

[3] K. Itaya, Prog. Surf. Sci. 58 (1998) 121.

[4] J. Engstrom, W. Tsai and W. Weinberg, Chem. Phys. 87 (1987) 3104.

[5] A. Lasia, J. Electroanal. Chem. 562 (2004) 23.

[6] N. Marković and P. Ross Jr, Surf. Sci. Rep. 45 (2002) 117.

[7] T. T. T. Hanh, Y. Takimoto and O. Sugino, Surf. Sci. 625 (2014) 104.

[8] H. Kita, J. Mol. Catal. A: Chem. 199 (2003) 161.

[9] K. Kunimatsu, T. Senzaki, G. Samjeské, M. Tsushima and M. Osawa, Electrochim. Acta 52 (2007) 5715.

[10] C. R. Henry, Surf. Sci. Rep. 31 (1998) 231.

[11] S. Dahl, A. Logadottir, R. Egeberg, J. Larsen, I. Chorkendorff, E. Törnqvist and J. K. Nørskov, Phys. Rev. Lett. 83 (1999) 1814.

[12] B. Hvolbæk, T. V. Janssens, B. S. Clausen, H. Falsig, C. H. Christensen and J. K. Nørskov, Nano Today 2 (2007) 14.

[13] S. Gudmundsdóttir, W. Tang, G. Henkelman, H. Jónsson and E. Skúlason, J. Chem. Phys. 137 (2012) 164705.

[14] E. Skúlason, G. S. Karlberg, J. Rossmeisl, T. Bligaard, J. Greeley, H. Jónsson and J. K. Nørskov, Phys. Chem. Chem. Phys. 9 (2007) 3241.

[15] G. Anger, H. Berger, M. Luger, S. Feistritzer, A. Winkler and K. Rendulic, Surf. Sci. 219 (1989) L583.

[16] C.-S. Shern, Surf. Sci. 264 (1992) 171.

[17] M. Minca, S. Penner, E. Dona, A. Menzel, E. Bertel, V. Brouet and J. Redinger, New J. Phys. 9 (2007) 386.

[18] Z. Zhang, M. Minca, C. Deisl, T. Loerting, A. Menzel, E. Bertel, R. Zucca and J. Redinger, Phys. Rev. B 70 (2004) 121401.

[19] J. M. Soler, E. Artacho, J. D. Gale, A. García, J. Junquera, P. Ordejón and D. Sánchez-Portal, J. Phys.: Condens. Matter 14 (2002) 2745.

[20] T. T. T. Hanh and N. T. T. Hang, Computational Materials Science 138 (2017) 295.

[21] P. Ordejón, E. Artacho and J. M. Soler, Phys. Rev. B 53 (1996) R10441.

[22] J. P. Perdew, K. Burke and M. Ernzerhof, Phys. Rev. Lett. 77 (1996) 3865.

[23] S. Gudmundsdóttir, E. Skúlason, K.-J. Weststrate, L. Juurlink and H. Jónsson, Phys. Chem. Chem. Phys. 15 (2013) 6323.

[24] Y. Waseda, K. Hirata and M. Ohtani, High Temp. High Press. 7 (1975) 221.

[25] W. Diño, H. Kasai and A. Okiji, Progr. Surf. Sci. 63 (2000) 63.

[26] A. A. Kumar, H. Jobic and S. K. Bhatia, J. Phys. Chem. B 110 (2006) 16666.

[27] I. Hamada and Y. Morikawa, J. Phys. Chem. C 112 (2008) 10889.

[28] H. Ogasawara and M. Ito, Chem. Phys. Lett. 221 (1994) 213.

[29] Y. Yu, J. Yang, C. Hao, X. Zhao and Z. Wang, J. Comput. Theor. Nanoscience 6 (2009) 439.

[30] W. Stenzel, S. Jahnke, Y. Song and H. Conrad, Progr. Surf. Sci. 35 (1990) 159. 